\title{
Feminino: uma construção a partir do não ser
}

\author{
Feminine: A construction starting from not to be
}

\section{Allícya Felizardo Feres da Silva1 ${ }^{1}$, Clarissa Queiroz Doro Dias' ${ }^{1}$ Bárbara Batista Silveira², Fernanda Cabral Samico ${ }^{3}$ \\ Como citar esse artigo. SILVA,

\author{
Resumo
} A.F.F; DIAS, C.Q.D; SILVEIRA, B.B; SAMICO, C.S. Feminino: uma construção a partir do não ser. Mosaico - Revista Multidisciplinar de Humanidades, Vassouras, v. 12, n. 2, p. 78-84, mai./ago. 2021

Nota da Editora. Os artigos publicados na Revista Mosaico são de responsabilidade de seus autores. As informações neles contidas, bem como as opiniões emitidas, não representam pontos de vista da Universidade de Vassouras ou de suas Revistas.

Este trabalho tem por objetivo apresentar algumas contribuições da psicanálise de Freud à Lacan sobre o enigma que é a mulher, partindo da fase pré-edipiana, bem como o complexo de castração e o complexo de Édipo, direcionando a pesquisa aos avanços teóricos que Lacan nos apresenta com suas conceitualizações das fórmulas quânticas de sexuação. Abordaremos, ainda, o campo do feminino e suas respectivas modalidades de gozo e de amor. Em seguida, discutiremos as influências dessas modalidades na forma feminina de amar. A metodologia utilizada foi a revisão de literatura de textos concernentes ao tema e o argumento norteador parte dos estudos de Lacan que dizem que não existe, no campo do Outro, um significante que signifique o que é ser mulher ou o que é o sexo feminino. O que há é um furo, e isso faz com que a mulher possa transitar entre dois campos, um fálico e outro não-todo. Como consequência dessa não definição do que é ser mulher, de alguma forma, resta a ela uma busca por algo que delineie sua existência e dê algum contorno à sua feminilidade, o que pode desencadear uma trama de amor e ódio com seu representante materno, e futuramente com seus parceiros. Partindo disso, Lacan lança o conceito de devastação, que está intimamente relacionado com o feminino e seus atravessamentos. Amor e devastação andam lado a lado e afetam diretamente os modos de ser e viver, trazendo desdobramentos significativos nas relações amorosas, o que acaba por refletir em nossa sociedade.

Palavras-chave: Feminino. Psicanálise. Devastação.

\begin{abstract}
This work aimed to present some contributions from Freud's psychoanalysis to Lacan on the enigma that is the woman, starting from the pre-oedipal phase. The work also presentes the castration complex and the Oedipus complex, directing the research to the theoretical advances that Lacan presents with its quantum formulas of sexuation. The feminine field, enjoyment and love are also addressed. Posteriorly, the work discusses the influence of enjoyment on the feminine way of loving. The methodology used was the literature review and the guiding argument is based on Lacan's studies that say that there is no signifier in the field of the Other that means what it is to be a woman or what is the female sex. What is there is a hole, and this makes it possible for the woman to move between two fields, one phallic and other not all. As a consequence of not defining what it is to be a woman, there remains a search for something that delineates her existence as a woman and gives some contour to her femininity, which can cause a plot of love and hate with your maternal representative and with your partners in the future. Starting from this, Lacan introduces the devastation concept that his related to the feminine and its crossings. Love and devastation are side by side and directly affect how to be and how to live, causing significant unfoldings in love relationships, which reflects in our Society.

Keywords: Female. Psychoanalysis. Devastation.
\end{abstract}

\section{Introdução}

Os primeiros estudos sobre a construção do feminino e o desejo das mulheres partiu de Freud, que buscou desenvolver teorias acerca da feminilidade e suas incidências sociais, tomando como base sua vivência na clínica com as histéricas e seus estudos sobre sexualidade. Apesar de ter apresentado avanços acerca do tema, ao final de seu ensinamento, Freud se depara com um impasse que o impede de chegar à uma conclusão no que diz respeito as particularidades do desejo feminino. Em uma carta à Marie Bonaparte, ele escreve: "A grande questão continua sem resposta e a qual eu mesmo não poderia jamais ser capaz de responder apesar dos meus trinta anos de estudos sobre a alma feminina: Was will das Weib? O que quer uma mulher?" (RODRIGUÉ, 1995, p. 128)

Lacan, em seu retorno à Freud, busca se aprofundar na temática e é onde percebemos um avanço palpável nos estudos, a partir da construção dos matemas das fórmulas quânticas de sexuação, que buscaram simbolizar, por meio da linguagem, algo que antes estava oculto. Lacan diz: "[...] é uma conquista da análise ter feito dele [do gozo] um matema, enquanto a mística

Afiliação dos autores

1Discente do Curso de Graduação em Psicologia da Universidade de Vassouras, Vassouras, RJ, Brasil

${ }^{2}$ Docente do Curso de Graduação em Psicologia da Universidade de Vassouras, Vassouras, RJ, Brasil

${ }^{3}$ Diretora do Corpo Freudiano de Vassouras, Vassouras, RJ, Brasil

*Email de correspondência: allicyafelizardoferes@outlook.com 
anterior só atestava sua experiência transformando-o no indizível." (LACAN, 2003, p. 487)

Os estudos do Lacan sobre os três tempos do Édipo, também nos ajuda a pensar a especificidade do feminino, sendo de suma importância o primeiro tempo, que persiste em a criança buscar ser o objeto de desejo de sua mãe, sujeitando-se a ela e aos seus desejos. No segundo tempo do Édipo, vemos que, pelo efeito da castração, o Nome-do-Pai, não opera na menina com o mesmo efeito que no menino, pois, devido à sua característica de já ter nascido castrada, ela não tem nada a perder. Iremos notar, durante o decorrer deste trabalho, que isso traz consequências tanto na saída do complexo de Édipo quanto nas relações amorosas futuras. (SAMICO, 2011, p. 59)

Retornando ao matema das fórmulas quânticas de sexuação, Lacan afirma que as mulheres são não-todas, pois possuem duas referências (ao falo e ao furo) e devido a isso conseguem transitar em um campo que está para além da lógica fálica, um gozo Outro, que impossibilita uma universalização da definição de mulher, e, ao mesmo tempo, emerge uma infinita possibilidade de criação, uma modalidade de gozo sem fronteiras. (SAMICO, 2011, p. 72) Lacan nos apresenta que não existe, no campo do Outro, um significante que signifique o que é ser mulher ou o que é o sexo feminino, o que há é um furo. Devido a isso, a menina busca na mãe durante toda a vida, significantes que possam lhe definir como mulher, mas nunca encontra, o que faz com que se veja desamparada diante de uma angústia gerada pela falta de identidade. Para dar conta desse vazio, lança mão de significantes fálicos considerados característicos do feminino que irão gerar uma sensação de completude temporária. A mãe, que também não obteve respostas definitivas a respeito de sua feminilidade, não é capaz de fornecer uma decifração que seja satisfatória o suficiente para que a menina possa constituir sua identidade como mulher, devido a isso, a menina, em um movimento de tentar se localizar em sua existência, tende a repetir nas relações com seus futuros parceiros(as) o primeiro tempo do Édipo, colocando-se como objeto de desejo do Outro na intenção de que este lhe dê essa resposta. (SAMICO, 2011, p. 60) Consequentemente, devido a essa postura de demandar um sentido de ser no outro, notamos relações potencialmente problemáticas e adoecidas, cercada de práticas demasiadamente abusivas e de dependência, que vem sendo destacadas no atual cenário de isolamento social devido à Covid-19, onde os casos de violência contra a mulher vêm aumentando significativamente. (HOLANDA, 2020)

\section{Feminilidade e feminino}

No início do século passado, Freud entra em contato com as histéricas e elas despertaram nele o desejo de descobrir mais sobre o que seria específico do feminino. Mais ainda, elas que inauguraram a Psicanálise a partir de uma súplica "me deixe falar". Assim, ao longo de sua construção teórica, Freud tenta dar contorno ao enigma da feminilidade, mas é em Lacan que conseguimos identificar uma teoria própria do feminino:

O que eu abordo este ano é o que Freud deixou expressamente de lado o "o que quer uma mulher?" Freud adianta que só há libido masculina. $\mathrm{O}$ que quer dizer isto? - senão que um campo, que nem por isso é alguma coisa, se acha assim ignorado. (LACAN, 1985, p. 108)

Em um primeiro momento, nos Três ensaios sobre a Sexualidade (1905), Freud trabalha a sexualidade feminina a partir da concepção da sexualidade masculina e conceitua toda construção teórica a respeito do complexo de Édipo em torno desse pensamento. Escreve, ainda, sobre a sexualidade dos homens ser acessível pela via da pesquisa, mas "a das mulheres, ainda se encontra mergulhada em impenetrável obscuridade.” (FREUD, 1972, p. 152)

Em 1924, em A Dissolução do Complexo de Édipo, Freud teoriza que o falo (primeiramente representado pelo pênis) é entendido como o único órgão sexual inscrito no inconsciente, sendo manifestado por sua presença ou ausência, e é exatamente essa ausência que irá significantiza-lo enquanto falo "se o falo tem relação íntima com o órgão masculino, é na medida em que designa o pênis enquanto faltoso ou suscetível de vir faltar." (LACAN, 1998, p. 172) A dissolução do complexo de Édipo para o menino se dá através da castração, que ao se deparar com o corpo da menina identifica a ausência do pênis e percebe a ameaça de castração. Assim, entra em um dilema onde precisa escolher entre manter sua integridade física ou manter sua catexia libidinal na mãe, o que vence é a integridade física e o menino abandona os conflitos edipianos. Essa catexia é substituída pela identificação com o pai. (SAMICO, 2011, p. 34)

Ao contrário, na menina, o complexo de castração dará início aos conflitos edipianos. Inicialmente, Freud nos traz a concepção de que o clitóris seria temporariamente um equivalente ao pênis, mas que não se sustentaria como um representante fálico. A fantasia da menina então começaria por pensar que seu clitóris iria crescer e ser tão grande quanto o pênis do menino e se deslocaria para o desejo de conceber um filho do pai. (SAMICO, 2011, p. 35)

Após 1920, com o texto Além do Princípio do Prazer, Freud introduz o conceito de pulsão de morte e é a partir disso que será possível um outro olhar acerca da feminilidade. Assim, podemos deduzir que há algo no psiquismo que está além do que é reconhecido no campo sexual, no campo do registro fálico. Há algo da pulsão de morte que não consegue ser delimitado. Em Lacan, 
veremos que o feminino se encontra nesse campo. "O feminino, portanto, assinalaria algo da pulsão de morte e não algo da pulsão sexual." (SAMICO, 2011, p. 31)

A partir disso, Freud reformula sua teoria sobre a sexualidade feminina, considerando sua singularidade, sua relação com o complexo de Édipo e os caminhos possíveis para tornar-se mulher. Em 1931, Freud, apresenta o texto Sexualidade feminina, aonde volta seu olhar para a fase anterior ao complexo de Édipo, que denomina de fase pré-edipiana, reestruturando sua teoria, concebendo que o primeiro amor para ambos os sexos é a mãe e que há uma longa história pré-edipiana para a menina.

A menina precisa renunciar ao seu primeiro amor com a mãe e isso trará consequências futuras nas suas escolhas objetais e em seu desenvolvimento libidinal. Por perceber a mãe castrada como ela, desenvolve uma hostilidade direcionada a mesma, com isso volta seu amor ao pai por acreditar que ele tenha aquilo que sua mãe não tem e foi incapaz de lhe dar. Mas fica o questionamento de como a menina transfere esse amor primordial com a mãe para o pai. (SAMICO, 2011, p. 38)

De alguma maneira, a menina culpa a mãe por têla trazido ao mundo tão faltosa quanto ela, no entanto, essa insatisfação corrobora para uma identificação com o corpo da mãe, deixando uma ambivalência de sentimentos. A intensidade de libido na relação mãe e filha e a longa duração são fatores que parecem destinados a terminar em ódio, ou pela mãe ou pelo parceiro(a) amoroso. Freud afirma que "[...] ao final dessa primeira fase de ligação com a mãe, emerge, como motivo mais forte para a menina se afastar dela, a censura por a mãe não lhe ter dado um pênis apropriado, isto é, tê-la trazido ao mundo como mulher." (FREUD, 1996, p. 241-242)

Lacan, em seu retorno a Freud, faz uma releitura do complexo de Édipo, intitulando três tempos: no primeiro, o bebê acredita que pode satisfazer os desejos da mãe se colocando como o que irá completá-la. "[...] é necessário e suficiente ser o falo." (LACAN, 1998, p. 198) No segundo tempo do Édipo, entra na operação o Outro com a roupagem de Lei, o Nomedo-Pai, assim a criança deixa de se identificar com o falo e é inserida nessa Lei. Já no terceiro tempo, o da dissolução do complexo de Édipo, para o menino, o pai irá mostrar, através das insígnias, que ele é possuidor do falo (ter o falo e não ser o falo), localizando-o como objeto desejado pela mãe, nesse momento acontece a identificação com o pai por ser também possuidor do falo. Com a menina, a metáfora paterna não tem tanto efeito, já que a castração para ela não tem tanto peso, pois já é marcada pela falta/ausência. (SAMICO, 2011, p. 56-59)

A saída do complexo de Édipo na menina fica então pouco elucidada. A menina demanda a mãe para que ela the dê um significante que represente o que é ser mulher, mas a mãe não pode respondê-la, pois não existe um significante que signifique o que é ser mulher, tornando essa identificação não-toda, e sendo impossível descrevê-la ou representá-la. "Esse apelo se repete eternamente e torna sem fronteiras a diferenciação a ser construída e mantida entre demanda e desejo, o que problematiza o surgimento do desejo como desvinculado do desejo do Outro primordial." (SAMICO, 2011, p. 65)

Lacan (1985) constrói as fórmulas de sexuação, Seminário 20: mais ainda (1972-1973), para dizer sobre o enigma da feminilidade, nela estariam representados dois campos, um feminino e um masculino, quem estaria inscrito em um ou no outro independeriam do sexo biológico, seriam formas de posicionamento como sujeitos perante a sexualidade, e teria uma diferença de gozo. Ou seja, as fórmulas quânticas de sexuação seriam "as únicas definições possíveis da parte dita homem ou dita mulher para quem quer que se encontre na posição de habitar a linguagem.” (LACAN, 1985, p. 107)

Nessa fórmula, Lacan usou da matemática para explicar algo que não está inscrito na linguagem. Ao estudarmos os campos, a partir dos símbolos, entendemos que no campo masculino, existe ao menos um sujeito para o qual a função fálica não funciona, e justamente por isso, para todos os outros a função fálica funciona. Já no campo do feminino, conseguimos interpretar que não existe um qual a função fálica não opera, logo, como nos aponta Lacan, não podemos dizer que para toda mulher há função fálica. Para Lacan,

Há um gozo dela, desse ela que não existe e não significa nada. Há um gozo dela sobre o qual talvez ela mesma não saiba nada a não ser que o experimenta - isto ela sabe. Ela sabe disso, certamente, quando isso acontece. Isso não acontece a elas todas. (LACAN, 1985, p. 100)

Assim Lacan (1985), ainda no seminário 20 (1972-1973), afirma que "A mulher não existe", no sentindo de que é impossível ficar totalmente no campo do feminino, pois isso retiraria toda e qualquer possibilidade de construção de linguagem, portanto, da construção de um sujeito. Podemos dizer então, que o campo do feminino está para além da lógica fálica, o que possibilita que a mulher transite de um campo para o outro. A partir deste pensamento, Lacan pode concluir que as mulheres são não-todas, pois devido a essa transitoriedade entre os campos (ao falo e ao furo), fica impossível uma universalização da Mulher, "Se ele se inscreve nela, não permitirá nenhuma universalidade, será não-todo, no que tem a opção de se colocar na $\overline{\phi \mathbf{x}}$ (lógica fálica) ou bem não estar nela." (LACAN, 1985 , p. 107) Lacan afirma que o gozo suplementar, localizado na lógica feminina, não é da ordem do significante, sendo assim, sobre ele nada pode ser dito, nada se pode saber, pois está inscrito além do falo, "as 
mulheres estão, em parte, submetidas ao gozo fálico e, em parte, a um gozo suplementar do qual nada sabem." (LACAN, 1985) Portanto, dizemos que o gozo feminino não é delineável, dessa forma, fazendo referência ao título deste artigo, o gozo feminino existe sem existir. Valdivia nos elucida que:

E é justamente esta inexistência que vai promover a sua existência enquanto ideal: tanto pelos homens, para os quais uma mulher é o seu sintoma, quanto para as mulheres, que se norteiam na tentativa de alcançar uma identificação feminina. (VALDIVIA, 1997, p. 23)

É impossível definir o que é o feminino, o que se faz é agrupar ornamentos e adereços fálicos que remetem à uma imagem que culturalmente fora definida como a imagem da mulher. Porém, como já sabemos, sendo impossível uma definição única do que é ser mulher, também é impossível definir um padrão de feminino. Talvez, pensando por esse lado, podemos entender o motivo de as mulheres estarem sempre sendo reféns diretamente, da moda, dos parâmetros estéticos, vestimentas e comportamentos delineados. Sendo as principais consumidoras da indústria da beleza, que criam uma ilusão de uma identificação com o que é ser mulher. (SAMICO, 2011, p. 61)

Com essa não universalização de algo que diga sobre o feminino, $\mathscr{A}_{\text {mulher só pode ser vista como }}$ única, não havendo um significante que signifique o que é ser mulher, elas lançam mão as insígnias fálicas que ilusoriamente nomeiam o que é próprio do feminino, mas não há nada que contenha essa resposta, cada adereço fálico não passam de máscaras, e a partir disso podemos pensar em uma construção exclusiva e particular para cada mulher, um vir a ser mulher, "há um trabalho que cada mulher deve realizar para construir sua "feminilidade" [...] que depende diretamente de como esta se posicionará diante da lógica fálica." (SAMICO, 2011 p. 41)

Como ensina Lacan, todos nós, como sujeitos, $\mathrm{XX}$ ou XY, transitamos entre os campos, ora estamos operando pelo campo do masculino, ora do feminino. Para que haja desejo, para que haja movimentação, é preciso que estejamos partindo da lógica fálica. Para as mulheres, não-todas, alcançarem algum tipo de consistência de identidade, é preciso que apostem que sujeitos que se localizam na lógica masculina a vejam como objeto de desejo de sua fantasia. Isso porque no campo do feminino, como já vimos, não existe algo que defina o que é $\mathcal{A}_{\text {mulher, e a única maneira possível }}$ para uma consistência de identidade é por via da resposta do desejo do Outro. (SAMICO, 2011, p. 69)

Ou seja, $\mathcal{A}$ mulher se encontra sempre "semi dita", "semi significantizada", "não-toda fálica", devido a isso, Lacan afirma que, a partir do momento em que ela é não toda, o artigo "A" tem que ser barrado ( $\mathscr{A}$ ).
(LACAN, 1985, p. 98) Não existe, no campo do Outro, nada que possa significar o que é ser mulher, o que existe, na verdade, é um grande furo, sem caminhos e sem respostas. Neste sentido, Samico (2011) esclarece que:

A saída edipiana das mulheres é um complicador para seus
futuros laços amorosos. Devido à condição não-toda fálica
que marca uma mulher, na operação de separação do Outro
primordial que é atualizada na saída edipiana, a menina pode
recuar da renúncia à demanda do Outro tanto pela expectativa
de poder obter uma compensação para sua falta-a-ser
enquanto sujeito, quanto obter uma identificação suficiente
para sua condição feminina. (SAMICO, 2011, p. 71)

Devido à falta de significantes que designam o que o é ser mulher, a menina pode se perceber capturada em uma crença de similaridade com a mãe, o que faz com que ela demande respostas. Essa situação pode resultar em uma resistência da menina a abrir mão dessa relação materna, o que contribui para dificultar ou até mesmo impedir seu processo de separação e o de constituição de um desejo próprio, um aprisionamento no laço com a mãe, podendo ter consequências avassaladoras. Para esse enredo, Lacan lança o termo devastação. (DRUMMOND, 2011, p. 4)

\section{Gozo suplementar e devastação}

A mulher busca por algo que delineie sua existência enquanto mulher e dê sentido à sua feminilidade. (SAMICO, 2011, p. 96) É preciso que a catexia libidinal seja depositada em outros objetos fálicos que possam dar conta de originar algum sentido à sua existência enquanto mulher. O que acontece quando nada é "encantador" o suficiente para que a mulher deposite sua catexia e não fique em uma busca alienante pelo gozo suplementar, é a devastação em suma, a busca eterna por algo que significantize plenamente sua existência. (SAMICO, 2011)

A devastação não se limita a reivindicação fálica que a filha faz à mãe, pois está além do registro fálico, também não é somente a similaridade imaginária de corpos entre mãe e filha. O que faz a devastação ser compreendida como uma modalidade de gozo suplementar é a infinitização da demanda de amor, que inicialmente começa com a mãe, mas se repete nas parcerias amorosas a posteriori, como nos aponta Drummond:

Uma mãe deverá se separar dos objetos de seu corpo
em sua relação com a filha. Se essa transmissão
não ocorre, a devastação será a consequência desse
deslumbramento narcísico que busca mais o amor
desenfreado do que o desejo. (DRUMMOND, 2011, p. 12)

Entendemos, então, que a ausência de um significante que diga o que é a mulher tem como 
consequência a possibilidade de um gozo infinito para o ser feminino, visto que, não há parâmetros delimitantes, o que faz com que a devastação decorra do deslumbramento que a lança em uma súplica de amor infinito, mantendo-a refém de uma relação que, como vimos anteriormente, jamais poderá ser correspondida. Isso leva, muitas vezes, ao desenvolvimento de uma angústia cuja consequência pode ser a destruição de laços libidinais e até a morte. De acordo com Soler:

\begin{abstract}
A dissimetria aqui prende-se ao fato de que a mulher, para se incluir no casal sexual, deve não tanto desejar, ou seja, moldar-se às condições de desejo do homem. Arecíproca nãoé verdadeira. Nas mulheres, portanto, a instância do semblante é acentuada, ou até duplicada por seu lugar no casal sexual, que as obriga estruturalmente, digamos, a se vestirem com as cores ostensivas do desejo do Outro. (SOLER, 2005, p. 33)
\end{abstract}

Zalcberg (2019) em De menina à mulher aborda a relação mãe e filha de forma bastante exemplificada, e nos mostra como essa relação pode ser devastadora. Ela nos ensina que a mãe que fica "colada" no eu da filha, continua reinando sobre ele, como quando era bebê, querendo adivinhar seus desejos e suas necessidades, o que desperta conflituosos sentimentos de ódio e gera um impasse na qual a única solução para essa separação seria a destruição da mãe. Entretanto, destruir a mãe seria destruir-se junto a ela, o que traduz então uma situação sem solução ou uma tragédia anunciada. (ZALCBERG, 2019)

Há mães que desejam acima de tudo prolongar a relação com esse ser tão dependente de seu amor e fruto de suas realizações pessoais, tendo dificuldade de renunciar à relação dos primeiros tempos, alimentando a ideia de que as duas na verdade, são uma. Isso acontece quando a mulher fica aprisionada na sua relação com a mãe. Como nos adverte Freud:

$\mathrm{Na}$ verdade, tínhamos de levar em conta a possibilidade de certo número de mulheres permanecerem detidas em sua ligação original coma mãe enunca alcançarem uma verdadeira mudança em direção aos homens. (FREUD,1996, p. 234)

Quanto ao amor, segundo Freud, os parceiros que a mulher escolhe seriam herdeiros da sua relação com sua mãe. (FREUD, 1931/1996) Por não ter conseguido um significante com a mãe, segundo Souza (2011), “a mulher deseja ser amada por um homem que a nomeie enquanto mulher, que the conduza ao lugar do "outro" sexo, o feminino." (SOUZA, 2011, p. 2) Essa posição do feminino, também difere na questão do objeto, a mulher se aproxima da forma da erotomania, na qual ela acredita ser amada pelo parceiro. A mulher goza ao sentir-se amada. A devastação para a mulher tem a roupagem de uma insistência de amor, uma demanda de amor infinita. Como apresenta Slongo:

A mulher se dirige ao homem pelo imperativo de que ele a ame incondicionalmente; que diga o significante de seu ser, que a faria, enfim, toda - o que retorna a ela como devastação, pois a coloca em relação ao Outro faltoso. É nesse ponto que a vertente feminina do amor assume um caráter erotomaníaco. (SLONGO, 2012, p. 2)

Segundo Passos (2017), a mulher nessa lógica, procura ser o objeto que falta, ou seja, o falo. Ela parece não avançar a outro tempo do Édipo, o ter/não ter o falo, permanecendo sempre na posição de ser o falo que irá completar, primeiro a mãe faltosa e posteriormente $o$ parceiro(a). Isso evidencia que o Nome-do-Pai não exerce tanto efeito, o que pode levar a mulher a ceder as vontades de seus parceiros, assim como se submetia as de sua mãe.

Com essa alienação, a mulher se posiciona como objeto de desejo do Outro e não tanto como sujeito desejante. A mulher implora ao Outro que lhe dê algum significante que diga sobre o feminino, ou seja, ela entrega ao seu parceiro o poder de dizer sobre seu ser, por isso a perda (ou a ideia da perda) deste amor torna-se devastadora, pois aponta para um vazio, para a não existência - o vazio do feminino. Pelas palavras de Drummond:

A perda desse amor pode trazer a irrupção de uma desfalicização do corpo, uma errância, uma despersonalização ou ainda uma ameaça de autodesaparecimento. Tais fenômenos decorrem da estrutura de cada sujeito e, certamente, de sua relação com a linguagem, o simbólico. (DRUMMOND, 2011, p. 11)

Com efeito, pensando como consequência da relação primária com a mãe, que é reeditada nos relacionamentos amorosos futuros, podemos pensar no índice de denúncias de violência contra mulher, que aumentou em $17 \%$ após o início das medidas de isolamento social em alguns estados brasileiros, conforme pesquisas da UFMG (HOLANDA, 2020).

Zalcberg ensina que "há algo que permanece não separado entre mãe e filha ao nível do Édipo, um resto que não pode ser simbolizado." (ZALCBERG, 2019, p. 193)

Por não ter conseguido um significante com sua mãe, a mulher carrega um vazio, que expõe o gozo indizível característico do feminino que não consegue ser capturado pelo simbólico. Assim, muitas mulheres vão se aproximando da condição de objeto - assujeitamento - diante desse real avassalador. De acordo com Naves:

Essa ideia de uma repetição a serviço de um gozo indizível nos abre a possibilidade de pensar a violência contra a mulher como impossibilidade de fazer barreira contra a emergência de um excesso inominável. (NAVES, 2014, p. 457)

Esse assujeitamento decorrente da falta de significante pode acabar contribuindo pra que essas mulheres se tornem vítimas de parceiros violentos. 
Principalmente se levarmos em conta a estruturação da sociedade que é edificada pelos pilares patriarcais, machistas, misóginos e sexistas que colocam a mulher em uma posição objetificada e submissa.

Pensamos então a necessidade de refletir sobre as condições de subjetivação dessas mulheres que experimentam a devastação, que mesmo diante de situações de violência pelo parceiro se mantêm alienadas e/ou dependentes daquele vínculo, evidenciando a repetição que, através de Freud (1920/2003), sabemos que está relacionada a pulsão de morte, contendo algo que não consegue ser delimitado e que foge do registro fálico. NAVES (2014) nos apresenta que a mulher em situação de violência tem a construção da sua subjetividade marcada pela passividade, pelo assujeitamento, o que propicia o sentimento de aprisionamento nessa relação, suscitando que a perda daquele vínculo poderia significar a desconfiguração do seu próprio eu, o desmoronamento de sua identidade, o que reforça questionamentos como "quem eu sou?" ou “o que será de mim sem ele?".

A origem dessa posição subjetiva de manter-se enclausurada num devastador aniquilamento subjetivo pode estar relacionada a um impasse no desenvolvimento de uma relação primeira entre a menina e sua mãe que, ao invés de lhe garantir condições de inscrição na trama edípica e suas consequências para a constituição de sua feminilidade, lhe arrebata a uma posição de fixação numa relação organizada para além do desejo, sustentada pela emergência de um gozo que não se significa. (NAVES, 2014, p. 455)

Para exemplificar como uma mãe pode influenciar na vida de sua filha e como isso pode ser extremamente opressor e condenar aquele sujeito à uma vida subordinada, trouxemos as falas ditas por uma mãe no filme Enrolados (DISNEY, 2011), uma adaptação do conhecido conto Rapunzel, onde é notável a semelhança das relações devastadoras, na qual a mulher sente que se perder aquilo que inconscientemente the constitui como mulher, que dá contorno à sua feminilidade, poderá também perder a vida, literalmente.

"Vá em frente e me deixe, eu mereço Deixe-me morrer aqui sozinha, por favor Quando for tarde demais, você verá, só aguarde Sua mãe sabe mais Acredite na mãezinha

Você não vai sobreviver sozinha Desleixada, mal-vestida, imatura, desajeitada [...] Digo isso porque eu te amo Mamãe entende

Mamãe está aqui para ajudá-la Só tenho um pedido [...] Nunca mais peça para deixar essa torre [...] Eu te amo muito querida Não esqueça disso

Ou você vai se arrepender Sua mãe sabe mais" (Enrolados, 2011, tradução nossa) ${ }^{1}$

\section{Considerações finais}

Sobre a importância da relação com o Outro materno para a menina, podemos inferir que grande parte do que a mulher se torna, tanto na busca da feminilidade quanto para suas relações amorosas futuras, diz respeito ao que viveu na infância, principalmente na fase préedipiana que ainda se apresenta muito velada por conter uma porção indizível, a porção do gozo suplementar, a qual a mãe e a filha compartilham e transmitem algo que talvez nem elas mesmas consigam acessar.

$\mathrm{O}$ tema debatido no presente artigo, nos remete a questões atuais e de grande importância e nos faz refletir sobre a construção de um feminino a partir da não existência de uma definição de mulher, ou seja, a partir do não-ser, considerando a importância da relação mãe e filha e como, de certo modo, determinará seu futuro como mulher e a forma como as relações com seus parceiros(as) amorosos futuros se darão. Talvez, olhando por uma perspectiva psicanalítica, poderemos enxergar com um pouco mais de clareza, mas nunca de forma generalizada, um dos principais fatores estruturantes que reverberam no comportamento e na organização psíquica das mulheres da nossa sociedade.

Durante este trabalho trazemos algumas questões que continuam sem respostas no que diz respeito a construção do feminino e a definição de mulher, como "O que é ser mulher?" e sabemos que não existe nenhuma resposta que consiga abranger todas as mulheres, pois como vimos, desde o início, na fase pré-edipiana, a menina já não "responde" da mesma maneira que o menino, pelo fato do Nome-do-Pai não produzir o mesmo efeito, uma vez que esta já nasceu castrada. É como se ela repetisse durante boa parte da vida o que Lacan nos apresenta como o primeiro tempo do Édipo, quando o bebê acredita que pode satisfazer os desejos da mãe e para isso se coloca como o falo que irá completá-la. A diferença é o objeto em que é projetada essa relação, que uma vez sempre direcionada a mãe, passa então a ser direciona aos parceiros(as) amorosos. Esse deslumbramento retroalimenta então uma relação devastadora, onde acredita-se que aquele Outro o pode dar um significado e uma definição de seu eu, e até mesmo uma nomeação enquanto mulher. Essa operação solidifica ainda mais a busca desenfreada pelo amor, e não pelo seu desejo, pois acredita que sendo objeto de desejo desse Outro que parece tão completo e definido conseguirá consistência e completude. O que acontece como consequência dessa busca é a devastação, quando percebe que aquele Outro também é faltoso e não poderá completá-la.

Dessa forma podemos ter uma ideia de porque as mulheres, em alguns casos, se colocam não tanto como um sujeito desejante, mas sim um objeto de desejo 
do Outro, pois essa na maioria das vezes, a partir da identificação com sua mãe, é a forma que ela encontra de posicionar-se enquanto mulher.

Mas isso não é uma sentença e não significa que com todas as mulheres será assim, afinal, não existe A mulher, e é impossível uma padronização e universalização desta. Devido a essa não universalização, abre-se um leque de possibilidades de ser, podendo ter um aspecto extremamente angustiante, como também, há a possibilidade de ser extremamente enriquecedor e possibilitador de processos criativos únicos para cada sujeito. Por isso dizemos que os analistas e os artistas são mulheres, pois o efeito de sua arte é criado a partir da desrrupção, em que o sujeito é retirado da lógica fálica, quantificável, e é lançado em uma construção onde não há limites e referências, apontando para uma infinitização de criação.

\section{Referências}

DRUMMOND, Cristina. A Devastação. Opção Lacaniana online, a. 2 n. 6 , p. 1-14, nov. 2011.

ENROLADOS. Direção: Byron Howard, Nathan Greno. Produção de Roy Conli. Estados Unidos: Walt Disney Pictures, 2011.

FREUD, Sigmund [1924]. A Dissolução do Complexo de Édipo. In: FREUD, Sigmund. Edição standard brasileira das obras psicológicas completas. Trad. de Jayme Salomão. Rio de Janeiro: Imago, 1972. v. XIX.

FREUD, Sigmund [1920]. Além do Princípio do Prazer. Rio de Janeiro: Imago, 2003

FREUD, Sigmund [1931]. Sexualidade Feminina. In: FREUD, Sigmund. Obras Psicológicas Completas. Rio de Janeiro: Imago, 1996, p. 113-134, v. XXII

FREUD, Sigmund [1905]. Três Ensaios Sobre a Sexualidade. In: FREUD, Sigmund. Obras Psicológicas Completas. Rio de Janeiro: Imago, 1996. P. 189-204, v. IX.

HOLANDA, Tiago de. Violência Contra a Mulher Cresce Durante a Pandemia. Universidade Federal de Minas Gerais, 7 abr. 2020. Disponível em: https://ufmg.br/comunicacao/noticias/violencia-contra-mulheres-crescedurante-a-pandemia. Acesso em: 17 mar. 2021

LACAN, Jacques [1958]. A Significação do Falo. In: LACAN, Jacques. Escritos. Rio de Janeiro: Jorge Zahar, 1998, p.92-703.

LACAN, Jacques [1972]. O Aturdito. In: LACAN, Jacques. Outros Escritos. Rio de Janeiro: Jorge Zahar, 2003.

LACAN, Jacques. O Seminário. Livro 20: mais, ainda [1972-1973]. Rio de Janeiro: Jorge Zahar, 1985.

NAVES, Emilse Terezinha. A Mulher e a Violência. Uma Devastação Subjetiva. Revista Subjetividades, Fortaleza, v. 14, n. 3, p. 454-462, dez., 2014

PASSOS, Carina Freitas. Amor Feminino: do Desamparo à Devastação. Dissertação (mestrado) - Universidade Federal de Uberlândia, Programa de Pós-Graduação em Psicologia. Uberlândia, 2017.

RODRIGUÉ, E. Sigmund Freud: O Século da Psicanálise, v.1, São Paulo: Escuta, 1995

SAMICO, Fernanda Cabral. A relação mãe e filha e a aposta libidinal da mulher. Dissertação (mestrado em Psicologia) - Universidade do Estado do Rio de Janeiro. Instituto de psicologia. Rio de Janeiro, 2011.
Lacaniana Online, a. 3, n. 8, p.1-6, julho 2012.

SOLER, C. O que Lacan dizia das mulheres. Tradução de Vera Ribeiro. Rio de Janeiro: Zahar, 2005.

SOUZA, Tharso Peixoto Santos. O lugar do desejo feminino frente à violência. Reverso. Belo Horizonte, v. 33, n. 62, p. 85-92, Set. 2011

VALDIVIA, Olivia Bittencourt. Psicanálise e feminilidade: algumas considerações. Psicol. cienc. prof. , Brasília, v. 17, n. 3, pág. 2027, 1997. Disponível em http://www.scielo.br/scielo.php?script=sci arttext\&pid=S1414-98931997000300004\&lng=en\&nrm=iso. acesso em: 30 nov. 2020 .

ZALCBERG, Malvine. De Menina a Mulher: Cenas da Elaboração da Feminilidade no Cinema e na Psicanálise. Rio de Janeiro: Edições de Janeiro, 2019. 